Subjects, Speakers and Roles*

\author{
Charles J. Fillmore.
}

*Sponsored in part uy the inational Science Foundation through Grant GH-534.2 rrom the Orfice of Science Information Service to the Computer and Information Science Research Center, The Ohio State University. 
Subjects, Speakers, and Roles

Charlas J. Fillmore

i. Whis report is a record of issues in the semantics of natural languages that have concerned me in the past few years, some of the things I have had to say about them, and some of the things that others have hac to say about then. There is nothing new in these pages, and there is much that is borrowed. I use numbered parafraphs mostly to create favorable associations--but also to make it obvious that I do not expent the reader to perceive here any structure beyond that of sheer sequince.

2. The traditionai first task of sentence analysis has been that of understanding and recognizing the highest-level division in a sentence, that jetween its subject and its predicate. On the tracitional account, the subject of a sentence is that portion of it which indicates 'the person or thing about whom or which a statement is made or a question asked,' and its predicate is that portion of the sentence which contains 'the statement or the question asked.'

3. In formal grammars of the type first discussed by Chomsky, the subject/predicate distinction is captured in terms of labeled coconstituents of sentences. The two major co-constituents of a sentence are a nounphrase (IPP) and a verbphrase (VP). A MP that is an immeaiate constituent of a sentence is defined as its subject; a $\sqrt{P}$ that is an imecifate corstituent of a sentence is its predicate. ' We may refer 
to this as the confimurational definition of subjects and proficatca.

4. In theories of grammar that derive from the work of Chomsky, a distinction is made between the deep structure of a sentence and its surface structure. Since both the deep structure and the surface structure are capable of having major co-constituents of the same types, and since the entities so identified mav be different in the deep and surface representations of the same sentence, it is necessary to speek of both deep structure and surface structure suojects and predicates.

5. It is of concern, therefore, whether the traditional account of tine sugject/predicate distinction applies to the distinction as it is cerined for the surface structure or the deep structure levei. Somethire abin to the traditionai distinction is apperent in the surface structure of some sentences. On the interpretation that the passive trassformation in English is meaning-preserving, it can be said that sentences $(5-a)$ and $(5-b)$ differ only in the identification of ore or another MP as subject.

$$
\begin{aligned}
& (5-a) \text { pianists play pianos } \\
& (5-b) \text { pianos are playea by pianists }
\end{aligned}
$$

There are arguments for saying, however, that while (5-a) is 'anaiytic,' (5-3) is 'synthetic.' Such' claims might be made for the interpretation that $(5-a)$ is a general statement about pianists and that $(5-b)$ is a Eeneral statement about pianos. :

6. It might be argued that either of the sentences in (5) can in ract be interpreted in either of the two mentioned ways. If that is so, then it follows that the iraditional account of the semantic 
relevanec of the subject/predicate distinction cannot be enptured by the conrigurational definition at all, on either the deep or the surâce structure level, uriless framatical description is a rood deal more subtle and sbstract than gramarians have thought.

7. The trinsformations which link deep structures with surface structures are taken, in the standard theory, to have in thenselves no semantic import. It has therefore been assumed that the semantic relevance of the subject/predicate distinction should be sought only in the deep structure.

0. liowever, the semantic role of deen-structure subjects apoears sot to be unirocal, at least when we look for the role of tinis entity in the nost strnirintforward way. The involvement of the entity nomed by the subject IT in the event or situation described by the sentences given below appears to be quite different in each case.

$(8-9)$ the boy slapped the firl:

$(8-b)$ the boy fell down

(8-c) the boy received a blow

(8-d) the boy has a toothache

(8-e) the boy has blue eyes

$(9-\hat{f})$ the boy $[$ his appearance] shocked me

In order for a semantic theory to relate THE BOY to the predicate expression found in each of these sentences, reference must of course be made to the 'subject' WP; but there appears to be no common notional property of 'subjectness" which semantic descriptions of these sentences can exploit.

9. A comitment to the view that 'subjects' defined in the 


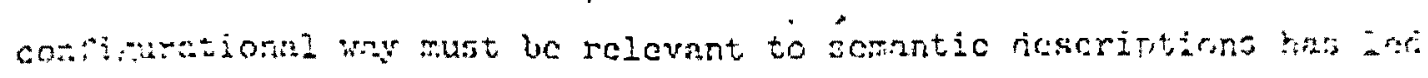
to two varietics of reanalysis. The first is mentioned in sectiona (10) $-(14)$, the second, briefiy, in (15).

20. Though it may not be possible to find a single semantic contribution for the subject role with all types of predicate expressions, it may at least be possible to find a unique subject role for eaci predicate wora, or, better, for each type of predicate word. There is a froup of verbs in Enplish which have both transitive and Intransitive uses and wich show the same IP role with respect to the subject in their intransitive uses as they do with respect to the direct object in their transitive uses. Pypical examples can be constructed with movement-veros like ROTATE or change-of-state verbs like BRENK.

$$
\begin{aligned}
& (10-a) \text { the cylinder rotated } \\
& (10-b) \text { Fred rotated the cylinder } \\
& (10-c) \text { the lens broke } \\
& (10-d) \text { Fred oroke the lens }
\end{aligned}
$$

12. Accorain to one attractive and popular proposal for capturing facts of the sort exhibited by the sentences in (10), the transitive sentences contain, in their deep structures, the intransitive sentences embedded to the verb CAUSE. 2 In each case the subject of the underIying verb CAUSE is the subject of the transitive sentence; the analysis interprets the sentence as sepresenting the proposition that the entity identified by the suoject IP of CAUSF is causer of an event characterized $y$ the intransitive sentence. The sentences (20-3) and $(10-i)$ can be thourht of as havinp in the1r aeep structure somethinf or the sort sugriested by $(11-a)$ and $(11-b)$ below: 
(11-a) Fred cause (the crlindor rotate)

(12-b) Fred cause (the lens breat)

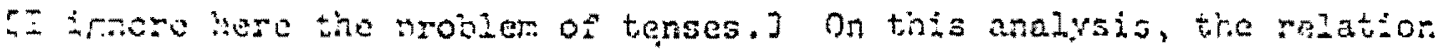
between the verb (ROTATE or BREAK) and its underlying subject is the same in both its (surface) transitive and intransitive uses. The appearance of these underlyinfly intransitive verbs in transitiveverb positions is a matter of surface detaíl.

12. The cases presented in (21) show a reconstruction that pives a unique subject/verb relationship for different 'uses' of the seme verb. Jy allowing, the relation between deen and surface structures to be more abstract still, it is possible to show semantic relations between two jifferent veros in a way that will reveal their underlyinh semantic comoralities; and, in particular for our purposes, will show tiat, for the given verb pairs, the role of the deep-structure subject is the same in both cases. Thus the deep structures of (22-a) and $(12-c)$ are something like what is supgested by $(12-b)$ and $(12-a)$ respectively.

$$
\begin{aligned}
& \text { (12-a) Peter killed the cat } \\
& \text { (12-b) Peter cause (the cat die) } \\
& \text { (12-c) Peter put the beer in the icebax } \\
& \text { (12-d) Peter cause (the beer to be in the icebox) }
\end{aligned}
$$

The replacement of CAUSR TO DIE by KILL and CAUSE TO BE by PUT is, apain, a matter of surface detail.

13. One midht object to the semantic equivalence of (12-a) and (12-b) on the grounds that (13-a) and (13-b) are not exact paraphrases. (13-a) Peter killed the cat in the attic 
(13-b) Peter caused the cat to die in the attic This ohjection is not critical, because it is nuite nossible so constrair-tine replncement by KILI of CAlbS TO DIF to only those situations in which the interior sentence has no ncrorbial motification. Tre locutive phace Ii TID ATPIC, in $(13-2)$, can oniy refer to the place where the causing took place.

14. Apparent difficulties of the sort mentioned in (13) are counter-balanced by the advantapes that this reanalysis offers in sentences like $(14-a)$ below:

(14-8) Peter put the beer in the icebox for three hours The complex sentence analysis makes intellitible the occurrence in this sertence of an adverbial of time duration (FOR THRTE HOURS), an edvero wich cannot be construed as qualifying the action which Peter persormea, but only the situation of the beer's being in the icebox. Efronts wich consider semantically complex verbs as inserted pretransfornationally are required to say of verbs like PUT that they ame used in referring to ections which have resultink staties and that they tolerate adverbial modiflcation of efther the precedinf, action or the resultinR state, but not (presumably)' both. observe (14-b)

\footnotetext{
(14-b) *Peter instantiy put the oeer in the icebox for three hours.
}

15. Certain researchers continue to seek a univocal interpretation to the deep structure if for all cases in which it occurs. These workers are required to assign the agentive or causing role to the deep structure subfect, and then to interpret all sentences which fail to contain a IP that has this semantic role as sentences which have no 
Econ structure subject whatever. 3 I will not say more of this sproach, since I do not consider it distinct-with respect to the 'arent' role--from an mpproach which assigns 'roles' to IPs explicisly.

16. The sccond pramatical function of MPs winth is defined confirinutionaliy within the stendard theory is that of tine direct ouject. On the traditional account, the role of the direct object in a sentence is tinat of 'patient' of the action referred to by the verb of the sentence, though deviations from this have lonk been understood and classified. By its confifurational definition, the object NP is identified as that WP which is an immediate constituent of the runin VP of the sentence. That the direct object relation is not semanticalizy univocal can be seen in the following sentences:

$$
\begin{aligned}
& (16-a) \text { I smashed the pumpin } \\
& (16-0) \text { I grew the pumpkin } \\
& (16-c) \text { I like the pumpkin } \\
& (16-d) \text { I imagined the pumpkin } \\
& (16-e) \text { I made the pumpkin into a mask } \\
& (16-f) \text { I made a mask out of the pumpkin }
\end{aligned}
$$

17. Defenses of the underlying univocality of the semantic role of the direct object can be pursued in the same style as those dealing with sentence subjects.

28. It would seen, however, that linfuistic theory ought to provide some way of distinguishing (1) the semantic roles which WDS have with respect to their predicate words, from (ii) facts about their positions in syntactic configurations, on either deep or surface structure levels. In some of my work I have tried to show how this. 
coudid be done.

19. Cortain verbs and adjectives scom to ronuire inheranty a Given nuber of ho in the sentences in which they take part. Anothor hay oi saytat this is that certain verbs and adjectives seem guite naturally to be reconstructible as n-place predicates in formulations within the predicate calculus. In descriptions of lopical n-place predicates, there is no special status'by which one or another of the ampuneats can be isolated from the rest, a strius that rould comsapond to the role of subject or object. The relation hetween unstructured (but, of course, ordered) n-place predicate expressions and syntactic configurations appears to require the positing of certain mechanical correspondence rules thich will meke use of the left-to-rifht position of the arduments in the predicate expression.

20. For. example, the verb Ralind-as seen in that sense of (20-a) (20-a) Harriet reminded Fred of Charlotte according to which Ered, on encountering Harriet, thourht of Charlotie-can be viewed at the semantic level as a three-place predicate, representable [ignoring tenses again] as (20-b)

(20-b) remind [Harriet, Fred, Charlotte],

a representation which is subject to the following syntactic configuration rules: the HP which identifies the first argument assumes the subject position; the UP which identifies the second argunent assumes the direct object position; and (a special rule) the NP which identifies the third arpument becomes part of a preposition-phrase which berins with OF.

21. Assuming that the underlying, sementic predicates have theit 
arount slots arranged in a fixed order, one can define converse relations between predicates in terms of their underlying expressions. Thus, the pnir LIKE/PLEASE will be definet: as 1-2 converses; the pair STLiBUY will be derined as $2-3$ converses: the rair BOB/STEAL Will be aefined as $2-3$ converses.

$$
\begin{aligned}
& (21-a) \text { John likes roses } \\
& (21-b) \text { roses please John } \\
& (21-c) \text { like }[a, b]=a \text { please }[b, a] \\
& (21-a) \text { Join sells roses to schoolglrls } \\
& (21-e) \text { schoolgirls buy roses from John } \\
& (21-r) \text { sell }[a, b, c]=d f^{b u y}[c, b, a] \\
& (21-a) \text { Harvey robs John of roses } \\
& (21-h) \text { Harvey steals roses from John } \\
& (21-i) \text { rob }[a, b, c]=d f \text { stea] }[a, c, b]
\end{aligned}
$$

22. Unfortunately, the method Just proposed requires that each converse pair be separately. identified, for each Ianpuaqe, by some defining expression like $(21-c),(21-f)$, or $(21-i)$. It is assuredly reasonable to demand of a semantic theory that observed converse relations among predicate words in natural languages be explainable from their meanings and their syntactic properties, not that they need to be stated by a set of definitions. For two expressions to be converses of each other is a surface syntactic fact; the descriotion of this situation should not depend on prior definitions made on underlying semantic representations.

23. One type of theory that would allow such explanations would require that all surface converse pairs have the same ordering of 
arpuments in their underlying, representation, and that specinl rules for subjectivalization and objectivalization be defined for one member of each such pair. The 'explanation' of the relation is that one member or the pair represents an irrepularity in the Eramar with respect to the subjectivalization and objectivalization mules.

24. A second approach is one which presents, with each underlying predicate expression, an unordered set of arfiment slots, eson of rhich is lajeled according to its scmartic role loz 'case' relationship) with the predicate word. It is this last position that I have taken. 4

25. One finds that a decision to speak of predicates, arguments and role types, rather than predicates, arguments and positions, make it possible to provide a sharp separation between what I take to be purely syntactic phenomena--tine left-to-right positioning of elements in the flow of speech-and facts about semantic interpretation. Two phonologically distinct predicate words may be interpreted as being semanticaly identical, having the same number of arguments in the same roles, but differing solely in the processes which arrange their elements into syntactic configurations. Each member of such paiss as BUY/SELI, TEACR/LEARN, SEND/RECEIVE, etc. 'take' essentially the seme argument types, in the same roles, but they differ as to the role identification of the argument whose name or description becomes its subject.

26. Such an explanation is not in itself fully satisfactory, however. It is quite frequently the case that differences in subject selection properties (Independentiy of the formation of passive 
santences) are correlnted with other kinds of fnets aibout predicate wobls. Two :emntically similar predicate words may differ, for examic, in the optionslity of the surface mnifestations of certain of their arfiments. In expressions containine SELd, for example, it is rot necessary to include a NP that mentions tine 'customer'; thus $(26-a)$ is a syntacticaliy complete sentence.

\section{$(26-a)$ Harvey selis shoes}

In expressions containing DUY, it is not necessary to include a ifP that rentions the 'merchent'; thus (26-b) is a syntactically complete sentence.

$(26-b)$ the girl bought some shoes Sinilarly, expressions containing ROB may leck overt mention of the 'Loot,' Just as expressions containing STELL may lack overt mention of the 'victim,' as is seen in the syntacticaly complete sentences $(26-c)$ and $(36-a)$

$(26-c)$ the boy robbed a bank

(26-d) the pirl stole some shoes.

27. The view which recognizes labcled, roles for the arfuments of a predicate expression makes it possible, furthemore, to speak of the relatedness of predicates having different numbers of terms. Two verbs can aiffer in that one manifests an n-place predicate and the other manifests an m-place predicate, the roles of the arguments that are present in the one and absent in the other accounting for the cifferences in the semantic interpretation of the sentences which contain them. This way of speaking provides a fairly natural Hay of speaking of the relationship between KILI and DIF, or that between 


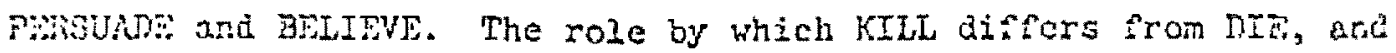
that by which PERSUADE differs from BLLIDVE is that of the individual that is 'agentively' involved in the events named by these rerbs. Apart from this difference, we are aealing here with pairs of synonms. 28. (It has been maintainea that the relation between words like these is more revealingly captured by the paraphrases with CNUSF Iike those mentioned in (10)-(14) above. The question is whether this reformulion is indeed significontly closer to the uncerlyinf conceptual reality to justify clains that have been made about the non-distincuness of semantic reprosentetions and deep structures of sentences. The Ford CAUSE itseli seems to have a substructure: to say that join caused the cat to die $1 s$ to say that John engaged in some activity and that activity directly resulted in the death of the cat.)

29. Anyway, the riew which separates semantic roles from Examatical functions as sharply as this proposed role-structure analysis does, makes it possible to explore, as a separate type of inquiry, the function of the subject/predicate division. There might be some difference between reasons for choosing the verb. BUY as opposed to the verb SELL, independently of the optional omissions mentioned in (26).

30. The verbs BurY and SELL refer to institutionalized interpersonal ectivities involving two participating parties, a sum of money, and goods or services that are to be provided for one of the participants by the other. There are no situations that can in tinemselves be distingulshed as buying situations or selling situations; but the choice of one or another of these verbs scems to make it possible to speak of a buylng/selling transaction from one of the 
nayticinants' point of view. One of the reasons for providine this Gisinction is to make it possible to determine the scope of rodicicaIEon o: certain kinds of adverbs aded to the sentence. I refer to the cifference we sense, with regard to the scope of SKILLFULLY, in $(30-a)$ and $(30-b)$

$$
\begin{aligned}
& (30-a) \text { he selis apples skillfully } \\
& (30-b) \text { sine buys apples skillfully }
\end{aligned}
$$

31. It even eppears thet there is a difference between the processes for determining the scope of adverbial modification and the processes rich determine the deeg-structure subject as aistinct rrom the sloface-suructure suoject. This can be seen by comparint sentences

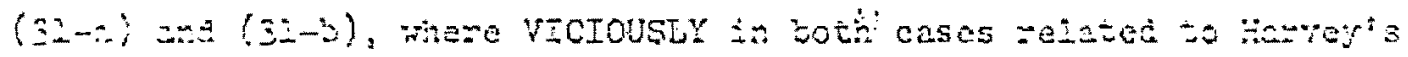

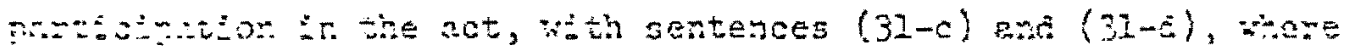

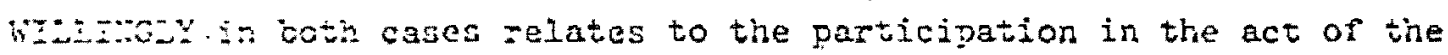
individual indicated by the surface subject NP.

(31-a) Harvey viclously took advantage of Mellssa

(31-0) Melissa was viciously taken advantape of by Harvey

(31-c) Harvey willinfly took advantage of Melisse

(31-d) Melissa yos willingly taken advantage of by Harvey 32. The proposal hinted at in (3I) supkests that there is some valiaity to the notion deep-structure subject; but the facts are not real. $2 y$ that decisive. It may appear instead that certain adveros may be introduced into a sentence as ways of qualifying one participant's role in the activity, the 1dentity of that individual being reconnized by the associated role tipe (Experiencer, Arent, etc.). Thus, Manne* adverbs of the type VICIOUSEX may appear"only in sentences having 


$$
-45 \stackrel{1}{-}
$$

unierlyius Agents, the scope of the adverb being unafected by the ultimate choice of surface subject. Pootal has noticed that the adverb' PERSOMLIY occurs only in sentences with subsective experience verbs and in conmection with the MP Identified as the Experiencerm-arain incependently of whether this MP is or is not the sentence subject. 5 Exarales like his are given below:

$$
\begin{aligned}
& (32-a) \text { personally, I don't like roses } \\
& (32-b) \text { your proposal doesn't interest me, personelly } \\
& (32-c) \text { *personally, you hit me } \\
& (32-d) \text { *personally, ontogeny recapitulates phylogeny }
\end{aligned}
$$

33. A theory which separates information about gransatical contrinations from insorgation about the natwe of the underiyting

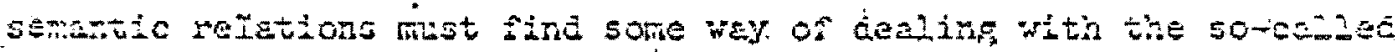
smotric preaicates. It should be possible, at some level, one migit thans, to say of verbs like MEE?, COIMCIDE, AGKEE, etc., that tiney require expressions raferring to: two or more exities, but such expressions may eppear in any of the severel ways provided by English grammar: as plural subjects, as in (33-a); as conjoined subjects, as in (33-b); or as palred KPs arranged in dfferent (depenaing on the verb) syntactic configurations, as in (33-c), and (33-a).

$(33-a)$ the boys met/agreed

(33-b) John and Fred met/agreed

$(33-0)$ John met Fred

(33-d) John asreed with Fred

It must oe afreed that no theory of mammar should be constrained in such a way that it has to reconnize two different verbs IEET, two 
ditfercint verus Maide, cte., in order to distinfruish the intransitive from the non-intransitive use of these forms.

34. This means recopnizing, for some $n$-place predicates, that they 'take' twio or more NPs in identical roles; but the main insights that have come from 'case grammar' or the theory of semantic role structure have depended on the assumption that no simple sentence requires the occurrence of more than one MP in a given role.

35. There do seem to be some differences in the conjoined subject as opposed to the distributed NP versions of symmetric predicate senterces, but for many of these the difference does not need to be seen as besic. We may consider egain the effect of adverbial modification, once spain taking the advero WILIIMGLY.

(35-a) Join and Fred willingly agree

(35-b) John willingly agress with Fred Cnot a paraphrase of $(35-8)]$

(35-c) John and Fred fought with heated mud

(35-z) John fought Frad with heated mud lnot a paraphrase of $(35-c)]$

36. For the examples in (35), the answer seems to bear on the procedure by which adverbs of various kinds, are to be introduced Into sentences. It mey be the case that in the symmetric-predicate sentence Itself, there is no necessary semantic difference that accompanies one subject choice or the other. Once a choice has been made, however, the sentence is limited as to the embedaing context which will welcome it. Thus, seatence $(36-a)$ requires the 'transitive' form of Mm in its embedded sentence, but only because the rerb ENJOY requires an 
icaristy between its subject and the subject of lts object sentence; and the subject of ENJOY is JOHN and not JOHN and MRY.

(36-a) John enjoyed meeting Mary

(36-b) John enjoyed (John meet Mary)

The point is that anslogous interpretations are possible for sentences with the adverb WILIINGLY, and with Instrumental hITHphrases. It is required merely that the adverb WILIINGLY be anaiyzed as a disguised embedding verb, as sugrested by (36-a).

(36-c) John willingly met Mary

(36-d) Join was willing (John met Mary),

and thet UIm-phroses be associated with parsphrases containing the vars USE, as suegested alrecay by Lakon.s. 6,7

37. It is frequently the case, horever, that apparent symetric predicates are not properly symetric after all. Sentences of the form $(3 T-2)$

$(37-a)$ IP resemioles $\mathrm{NP}$

are extensionally symmetric if both NPs are definite rererring expressions, but otherwise (as in $(37-b)$ ) not.

(37-b) your brother:resembles a horse.

My interpretation of the Similarity Predicates is thet one of the terms has the role stimulus (or what I would call Instrument, but with " the notion of 'implement' abstracted away), the other has the role Theme (or what I have called object in my earlier writinfs), and the sentence is an expression of a 3-place prealcate in which the third and phonetically absent exgunent is the Experiencer, which is understood, when unexpressed, to be identified with the speaker or the

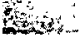


sentence. The Stinulus must be expressed" as a referring expression, but whe Theme need not. The sentence means roughly that your brother as stimulus evokes in me memortes of horses. [Incidentally, the vero RaYIN, mentionea earlier, has a very similar structure, except that with it an $\mathrm{NP}$ representing the Experiencer must be present in the surface sentence.J

38. For many other so-called symmetric predicates there are arguments that the associated MPs do not serve in absolutely identical roles. It is difficult to capture such information in the face of the wide range of facts accounted for in the conjoined-subject source aninysis of Latoff and Peters, ${ }^{D}$ but such a reanalysis may prove to be recessary aiter all. fund this is to say roting of the problem oi dealing with the Asymetric Joint Action Predicates of the type discussed by a prominent generative semanticist (writing under an alias).

(38-a) Fred and Sheila were blanking

(38-b) Fred was blanking Sheila

(38-c) "Sheila was blanking Fred

39. The occurrence of quantifying expressions of various types sears to be constreined in fairiy mosterious ways according to the surface arrangements of. the MPs in a sentence. Lakoft's 'derivational, constraints'10 fail, as far as I can tell, to account for the particular set of misteries I have in mind. In general, DEVELOP Irio and DEVELOP OUT OF are 1-2 converses (al though they" also have a use as 2-3 converses of 3-place predicates); but there is a skewness in the pattern of quantification compatible with these expressions, as 
can be seen by comparing the paraphrasability facts shown below;

(39-a) every acorn developed into an oak

(39-b) an osk developed out of every acorn [a paraphrase

$$
\text { of }(39-a)]
$$

$(39-c)$ every oak developed out of an acorn

(39-d) *an acorn developed into every oal lnot a paraplirase of $(39-c))$ :

[Jeffrey Gruber ifirst drew my attention to sentences $(39-a, b, c, a)$.

Similarly, MAKE IIITO and MAKE OUT OF are 2-3 converses of 3-term prodicates, and the patterns seen above are repieated, only this time betreen the direct object and the object of a preposition.

(39-e) I made every $l o g$ into a eanoe

(39-F) I mace a canoe out of every $\log$ [a paraphrase of $(39-e)]$

(39-6) I made every canoe out of a log

(39-h) *I made a lob into every canoe (not a paraphrase

$$
\text { of }(39-8)]
$$

40. Lest the data of $(39)$ be thought of as involving exceptional properties of 'verbs of physical transfomation', we can show here that verbs which are thenselves converses of each other (FOLLOW and PRECEDE) exhibit similar patterns with their own passive counterparts

$(40-a)$ a Sunday follows every. Saturday

(40-b) every seturday is followed by a sunday [a para. phrase of $(40-8)]$

(40-c) every Sunday follows a Saturday

(40-d) a saturday is rollowed by every sunday [not a Daraphrase of $(40-c)]$ 
(40-5) a Saturday precedes every sunday

(40-f) every sunday is preceided by a Saturday la paraphrase of (40-e)].

(40-5) every Saturaay precedes a Sunday

$(40-h) \approx a$ Sunday is preceded by every Saturday [not a paraphrase of $(40-8)]$.

I suspect that the data offered in sections (39) ana (40) are ultimately explainable in terms of 'derivational constraints' of the kind discussed by Lakoft. A reason for bringing them up in this report is that they show restrictions of a fairly interesting sort that relate both to the fomation of aeep-stmucture subjects (put differently, to the chose of perticular mexbers of a converse part) and to the formation or surface-structure subjects.

41. In $5 y$ proposals on 'case Branmar' I have assumed that the role types which one can refer to in describing the semantic structure of predicates make up a universally valia enc reasonably well-speciffied set of concepts. I have assumed, too, that the role types are themselves unanalyzables, corresponding to elementary perceptions on the part or human beings concerning such matters as who did it, who experienced it, where it happened, what the result was, where a thing that moved ended up, where it started out, what moved, enc a fer others. I have convinced myself that certain role notions recur ccross widely variant lanpligges, namely those for which one finds usefui the terms Agent, Instmument, Location, Object, Patient, etc. I have found that many valid assertions about lanprages can be made by describing the structure of their sentences in these terms. The 
most serious dificulties have had to do with specifying exactly what this small set of role types consisted of, and determining whether or not it wou"d turn out to be necessary, at least for some verios, to interpret certain arguments as serving, two role functions similtaneousiy.

42. This last difficulty is that of seeing the relationsnip between the case functions that seem to be involved in almost every sentence--such as, for example, thöse. I named in the last section-and the sort of role structure that is involved in the description os particular kinds of institutionalized transactions for which a 'sield' of vocabulery may exist in a language. I have in mind the roies of customer, merchent, goods, and instrument of excherge in the rocebulary field thet includes BUY, SELi, PRY, DICKER, ete.; anc those of defendant, Judger, deed, victim, etc., in the field that includes verbs like ACCUSE, CRITICIZE, FORGIVE, APOLOGIZE, CONFESS, CONCEDE, JUSTIFY, EXCUSE, etc. I am at the moment ready to assume that it may be necessary to treat the semantic roles of arguments on two 'levels'. I mean that I'may want to be able to say that in expressions with BUI there is one arpument which has Customer function on one 'level', Agent function on another, whereas in expressions with SELI, the argument wich has Agent function is the Merchant, not the Customer. In what follows I. leave open the possibility that the roles associated with a predicate yord may not bear a one-to-one correspondence with the arguments associated with it.

43. A preat deal of attention has been fiven in the last year or two, in linguistic circles, to the fact that the semantic description 


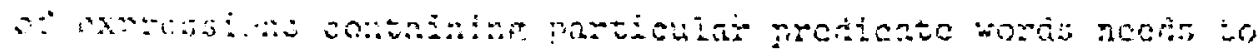

distinruish what the speaker of the sentence mirht he sayinr. (or 'doinf in sayinf') explicitly from what he is said to nresuppose about the situations concerning which he is speaking. The apparatus for formulating the presuppositions will need to refer to the entitics wich serve particular role functions with respect to the event or situation identified by the predicate.

44. In my aescription of verbs of judping, 11 for example, I have pointed out that for sentence $(44-8)$

(44-a) Harvey accused Fred or rriting the letter.

the utterer of the sentence presupposes (that Harvey presupposes?) that someon's having aritten the letter in question ras bad, and whet he is ceclering, in uttering $(4-4-a)$, is that Harvey claimed that Fred is the one who did it. On the other hand, for sentence (44-0)

(4i-o) Hervey criticized Fred for writing the letter the speaker of the sentence presupposes (that farvey presupposes?) that Fred was the one who wrote the letter, and is declaring, in uttering (44-b), that harvey claimed that for Fred to have written the letter was bad. The force of Harvey's utterance in (44-a) is what is presupposed in $(44-b)$, and vice versa.

45. Paralleling the pair of words offered in (44) is the pair CREDIT and COMERD. These aiffer in that where ACCUSE and CRITICIZE carry the idea of blameworthiness, CREDIT, and COMARD carry the idea of goodress. That' is, in $(45-\theta)$ someone's having written the letter is Juazed in advance as beinf good, and what is communicated is that Harvey cleimed Fred did At; in (45-0) Fred's responsibility is pre- 
supposed, and what is communicated is that larvey claimed that what Frod did was good.

(45-a) Hervey credited Frea with writing the letter

(45-b) harrey comenced Fred for witing the lator

46. The distinctions seen here are analogous to those which J. I. Austin recognized in an embigulty of BLAME and in the pair of vords EXCUSE and JUSTIFY.

47. Sone of the verbs of judging are illocutionary verbs, as are, for those I have mentioned, ACCUSE and COMMEND. What this means is that, for those verbs of judging which are capable of serving, as 'explicit performatives' or 'illocutionary force indicating devices," a presuppostitionel analysis of them comes to show certain fesemblances to, say, Searle's analysis of promising and other illocutionary verbs. The aralysis of illocutionary acts along the line developed by secrle 12 is a special case of the analysis of the type I have in mind (especially as it concerns presuppositions), beinp special only in that what is presupposed of the subject of the verb must be true of the speaker of the utterance, and that a performance of the utterance under the first-person-present-tense conditions appropriate to performatives 'coints as' the performance of an act which has extralinguistic validity.

48. Searle's type of anglysis can easily be extended, workine. in the other direction, to the descrintion of non-linmuistiemact verbs. Thus the 'preparatory condtion' for a valid utterance of (48-a) $(48-a)$ Sheile borrowed five dollars from Fred is that Fred had five collars; the 'sincerity condition' is that 
Sheila intencs to five Fred rive dollars at some time in the future; the 'essential conation'-which here, however, cannot be matohed With a rlile wich governs the use of an operative lingistic expression-is trea Sheize has undertaken an ooligation to return Pred his five solzars some day.

49. (Tnis is not to say that one can accept all of what searle has to say about promising. His account fails, as far as I can tell, in one or two respects. For example, he claims that in performing a valid promising act one hes taken on an obligation to perform in a particular way in the future. If this is so, then the utterances, on a mother's part, of the resssuring words $(49-\mathrm{a})$ or $(49$-b) must be ceicetive es acts of promising.

(16-a) I promise you that your father will come back (49-0). I promise you that the sun will come up again tomorrow.

If it were seen, hovever, that in making a promise one provides a $4^{*}$ personel guarantee of the (future) truth of a statement, such promising acts would not need to be described as defective. Promising of the type Searie has in mind must be understood in terms of guarantees of the (future) truth of statements whose propositional content contains descriptions of acts to be performed by the meker of the promise. (That is, in which an expression referring to the maker of the promise is in the Agent role.)

50. (A second quibble might be raisea in connection with Searle's hint that MUPEATEN is the unfavorable consequence counterpart of PROMISE. This is wrong because (i) threatening acts do not need to 
be (accompanied by) Iinguistic acts', and because (ii) in threatentns, somebody, one does not take on an oblipation to do anythinp. You ean succed thoroughly in threatentng me by merely saying that you mi fyt consider beating, my brains out. It may. be, horever, that I am confused by an ambiguity in THREATEl between an illocutionary and a perlocutionary sense. I know, for example, that one can declare that threatening words are inerfective either by saying, (50-a) or $(50-5)$.

(50-a) you can't threaten me [perlocutionary]

(50-b) your threats don't bother me [illocutionary.)

51. We have thus seen that the semantic analysis of orainary isnguge sentences, in order to incorporate observations and ruies ebout illocutionary force, must inelude in its scope weys of desling with the particlpants in the speech act itseli. The traditional term for dealing with matters of this sort is deixis. One speaks of person dexis (references to the speaker and the addressee), piace deixis (references to the locations of the speaker and the adaressee), time deixis (references to the time of the speech act), as weli as references to portions of the utterance itself (discourse deixis), and references to the relative social statuses of the speech act participants (honorific systems, etc.).

52. In the description of certain predicate words, there is $a$ a necessary reference to deictic features, especially in the description of the presuppositions or 'preperatory conditions'. The prime exnmole of this for English is the vero Cone. ${ }^{23}$. In sentences of the form piven in $(52-e)$ 


$$
(52-a) \text { o (object) comes to } P \text { (place) at } T \text { (time) }
$$

it is presupposed of $P$ that it is either

(i) where the speaker of the sentence is at the time of Htterance; or

(ii) where the addressee of the sentence is at the ime or utterance; or

(iii) where the speaker of the sentence is/was/will be at it or (iv) where the addressee of the sentence is/was/will be at $T$.

53. Sentences containing no other dejctic references permit all four presuspositional possibilities, as in (53-a)

(53-a) Fred will some to the of fice tomorrow But others are limited because of presuppositions associated with other deictic parts of the sentence. Thus, (53-0) presupposes either that you are there now or that you will be there tomorrow, but not that I an there now nor that I will be there tomorrow at the time I arrive; and (53-c) presupposes that I will be there tomorrow at the time of your arrival, or that you are there now while I am speaking.

(53-0) I will come there tomorrow

(53-c) you will come there tomorrow

54. (A full semantic theory of a language must additionally take into account the fact that there is an extended or aispliaced use of deictic features corresponding to the ways in which the speater of a third-person narrative 'identifies' with one or another of the characters in his narretive. If one of the basic functions of deictic categories is to express airectly the speaker's role or viewpoint with respect to his subject matter, in the 'aisplaced' use the speake= 
perioms some kind of psycholopical 'identification' with one of tite parties in his rarrative. It seems that instances of 'risplaced ero' can be seen in sentences like $(54-8)$, where the author is interpreted as vicying the situation from Harry's point of vier, rather than Irom Fred's or Bild's.

(54-a) Fred came to where larry was, and then Farrf ient to where Fred was

In $(54-b)$ the suthor is aloon; sentence $(54-c)$ is unacceptajie.

(54-b) Fred wert to where tarry was, and then Harmy went to where Bill was

(54-c) "Fred came to where Harry was, and then Harry cane to where Eill was

The pinenomenon is quite andogous to the distinction provided by scme (e.g., Aigonquian) Ianguges between 'proxitnative' and 'Ouvirive' trire persons. It hes been noted that the proximative forns are only associated with one individual in a third person narrative at a tire, and that the sritch in the application of the form from one individuel to another corresponds to a shift of point of view in the development of the narrative.)

55. As stated earlier, it is the inclusion of reference to speech act participants in semantic descriptions which makes possibie the incorporation of matters of 'illocutionary act potential' in the description of sentences. An attractive view is that the 1llocutionary force of a sentence is represented in the deep structure of that sentence, or at least that what one might call the 'straiphtforwad 11locutionary act potential' of a, sentence should be so represes..... 
Wiscoes that novio al conversntionat sentences should be proviacd Whi this sore of stipustructure at their tepect represcntation hos boen ortered by hoss. For sentences whose utterances have the \$locutionsy force of asserting or infoming ('dectardan'), there are reasons, for, believing that there is, in the deap structure, a silent lilocutionery verb or declaring havind a first-person lpent NP, second-person Dative $P P$, and having the non-stlent part of the sentence as its direct object. ${ }^{4}$

56. The occuryence of adveros like Pansovally is now permitted a consistent eccountinfy. The adverb occurs in sentences vith 'psycho-

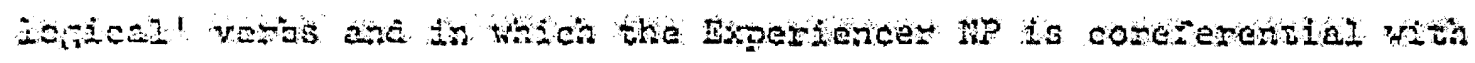
the ficent ke of the immedately comanding linpuistic-ect verb. finere the upger 1 linglistlenet yero is apperent in the surfece strucure,

- Ars obsentaton wecoust for the eceptabillty of $(56-a)$ as opposed to $(56-b)$.

(56一) Fred said that he personaly dislikes roses $(56-b)$ Fred said that Martha personaliy als lkkes roses

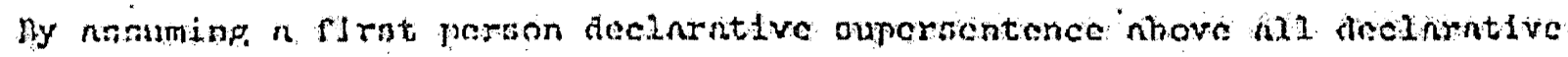
sentences, one can account, In Ross's fashion, for the acceptablifty of $(56-c)$ as opposed to $(56-a)$. (56-c) personally, I dajlie róses (56-d) Fersonally, Fred dislikes roses

57. Anelorously, the pleading-rora pIEASE occurs only in scriences invicditedy commanded by verbs of ordering or renuesting. The requiroment is that the Arent NP of the interior sentence be coreforestifu to the Dative NP of the orderlan or requesting verb. Whare the ordering or requesting verb is present in the surface 
sentence, this accounts for the acceptability of (57-a) as oprosed to $(57-3)$.

$$
\begin{aligned}
& (57-3) \text { I told Fred to please leave the room } \\
& \text { (57-0) .I predict that you will please leeve the roo: }
\end{aligned}
$$

Assuminf that imperative sentences are contained in sident performative structures of ordering allows one to explain, by the same principle, the acceptability of $(57-c)$ as opposed to $(57-d)$.

$$
\begin{aligned}
& (57-c) \text { please leave the room } \\
& (57-\tilde{a}) \text { *Fred please left the room }
\end{aligned}
$$

58. One question about the presuppositionel structure of sentences that I have not discussed is that of who does the presupposing. Fre-

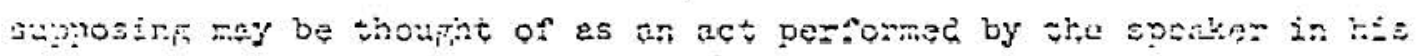
production of the utterance, or as an act irplited ty the spetres to one or more of the Incividuals whose properties or actions are cescribed by the utterance in question. I assume that there wizl bemuch more to say about such matters after one has seen the results of Lakoff's explorations into the logic of 'worle-creating veros'.

59. The view of semantic interpretation that I have been assuming is roughly this: I believe that, given a full kramatical description of a sentence, with complete semantic descriptions of the lexical items it conteins, it should be possible to 'compute' the full semantic description of the sentence, including, of course, information about what its utterers must presuppose to be true, including its utterers imputations of presuppositions to'individuals described or referred to in the sentence. This 'computation' will involve many types of grammatical fects and a great many subtle properties of lexical items. 
The vien is remesentative of what is called interpretive semantics, but it is one rich involves operations which are quite distinct Fom silose proposed in the earliest presentations of interpretive sembntics. Operations involving selection restrictions are here replaced by an understanding of presuppositions; this has the effect of cissolving the problem of aiscovering the boyndary between the semartic properties of words (e.f., nouns) and the physical properties of the things to which the words could be correctly epplicd. Interpretive semantics is one which relcomes lexical items that contain in their definitions variabies not found in the expressions that contain them. These variables are relevant to the sementic intopuctavion of sutences, because there are situations in wich necdications involvint these variales are more essential parts of

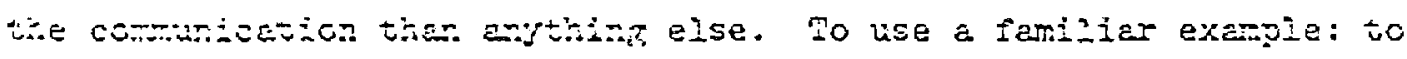
say of Frea, Iiteraily, that he is a bastard, is to say of his. mother that she was not married on the day he was born. And that is to 'refer' to soneone not mentioned in the original assertion.

60. The alternative vier, within what has come to be calzed 'generative scmantics', 15 has it, if i understand correctly what is roing on, that all of the information relevant to the semantic intempretation of a sentence must be present in a representation of the deep structure of that sentence, and that, in fact, there is no level of 'deep structure' that is distinct from the level of semantic representation. If in the end the 'generative semantics' view turns out to be more raiid-and I con't know what I an revealing aoout myself to adrit that I find the arpuments favoring generative semantics over- 
Hivelinine but somehow not coercive--then descriptions of the tyre $i$ an capable of coming up with through my work will rall in piece, withis the correct theory, on the level of lexicolory. I believe, tingt is, that the observations about the meanings of lexical itens, the relations which must be described in charecterizing the senantic structure of expressions containing specific lexical items, and the format for expressing these facts, can be exactly the seme under either view.

6i. It is the apparatus for dealing with presuppositions thet makes me retain faith in the interpretive-semantics position. It Is Ercauertly possible to state the presuppositions of a sentence in trae somon a schera hibich operates on the mremetical cescription (in ract, ofter enough; the surface brenatical descriotion). If ite

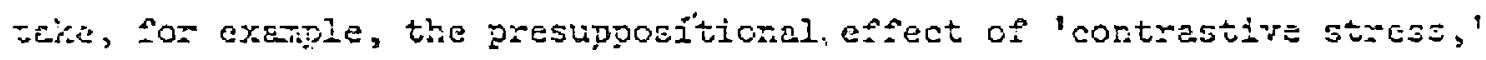
it generally seems to be the case that a sentence of the form sugRestea by $(62-a)$

(6l-a) $X \underline{Y}$ [where underlining represents emphasis] is associated with the presupposition surfested by (6I-b)

(61-b) it has been suggested that $X Y^{\prime} Z$ [where $\left.Y^{\prime} \neq Y\right]$ Given this formula, we can figure out in what contexts one mifint say $(61-0)$

(61-c) It's an essay in descriptive metapinysics. by imagining what different type of metaphysics somebody might have alluded to in the utterances that preceded $(61-c)$. If it is impossible for us to do this--because, say, we know nothinf whetever about how the word METAPHYSICS is used--ke cannot understand the presuppositional 
contcat of $(6 i-c)$, but we know somethine ahout how to acouire this understandeg.

62. Perha;s the main reason I cling to views of interpretive semantios is that $I$ an unconsciousiy guilty of the much-discussed $\sin$ of confusing the linguistic technical term 'generete' with the psychologically more immediately understandable notion 'produce' (as in 'produce utterances'). I so frequently find myselit speaking without any understanding-of what I am saying that I quite naturally think of the ebility to produce a sentence as involving essentigliy different principles from those that are employed in figuring out what if anythisร 
Footnotes

${ }^{2}$ Sce loun Chomsicy. 1965. Aspects of the Theory of Bytax, X.I.m. Press, chapter 2 .

2sce, e.r., James D. Mccarley. 1969. Lexical insertion in a transiomationel prammer without deen structure, in Bsiley, C-i., 3. J. Darden ard A. Davison, Papers from the fourth refionai metsrif of

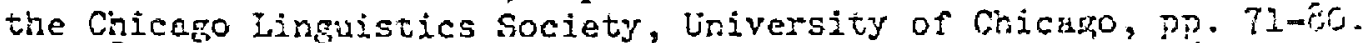

3For examples of this approach see Parbara Fall. 1965. Sliject ard object in English, M.I.T. Ph. D. dissertation, and P. Grenory Lee. 1960. Subjects and agents, OSU Workinf papers in linpuistics lio. 3 , Columbus, pp. 36-113.

"See, e.g., my The case for.case. 1968. in F. Bach anri $R$. Hams, eds., Universals in Iinquistic theory, Holt, Pinehart ? Wiston, pp. 1-65, and Lexical entries for verbs. i968. Foundations of Language $4.4 .373-393$.

SPaul M. Postal, Cross-over phenomena, in Specisication ara utigization of a irensformational gramer (Scientific report lo. 3), Yorktown Kejkhts, low York: IBk Jesearch Center.

Goe Geore Lakoff. 1968. Instrumenta? adveros and the corcept

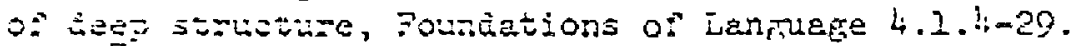

Tion tiriner ciscussion of the netters taken up in sections $19-$

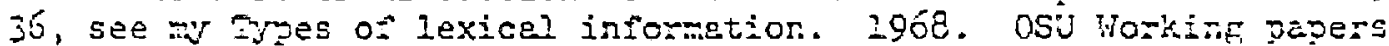
in 1inguistics 00.2 , pD. 65-103 (to appear in Semartias: $d$ intercisciplinary reader is ghizosophy, linguistics, anthropozogr and

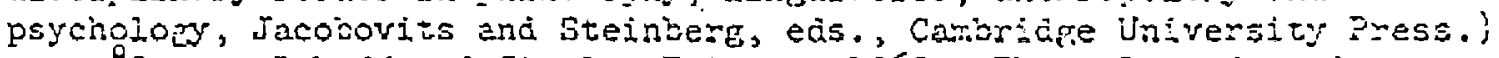

8 George Eviroff and Stanley Peters. 1969. Phrasal confunction snd symetric predicates, in Kodern stwaier in Enrish, Davia ReijeI and Sanforo Schane, eds., Prentice-lail, pi. 113-142.

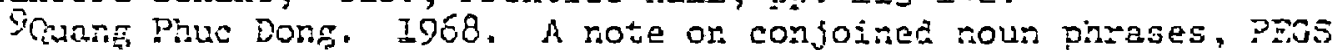
(usaujistied).

10 Gerre Lakof:. 2069. On derivational constraints, in Pexers from the firth repional meeting of the Chicaro Linpuistics Society, Chicego, pp. 117-139.

11For a somewhat more detailed discussion, see my Verbs of Judring: An exercise in semantic description. 1969). Papers in Linpuistics 1.1, Florida State University, p. 91-il7.

l2.John R. Senrle. 1969. Sneech Acts: An essay in the philosophy of language, Cambridge University Press,

13 See my Deictic categories in the semantics of 'come'. igf́. Foundations of Langugge 2.219-226.

14 For e persuasive statement of this analysis, see John R. Ross. 1968. On declarative sentences, to appear in Jacobs and Roseniban, Readiprs in Frgeish Pranstormational Grammar, 31 aisciell.

IS See, for a survey of the literature on and the arpiments for renerative semanties, Ceorfe Lahot:'s Generative semanics. To appear in Senn Steintert and Leon Jakobovits, eds., Semantics: hr interciscinitrary reader in philosophy, linnustics, anthronology and csycholory, Camoridge University Press. 